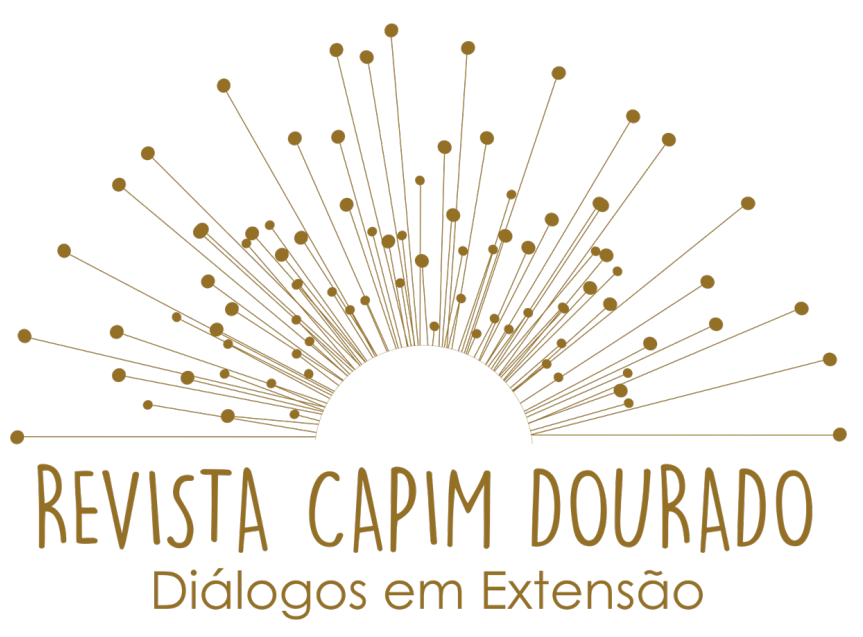

ISSN n² 2595-7341

Vol. 3, n. 2, Maio-Agosto, 2020

DOI: http://dx.doi.org/10.20873/uft.2595-7341.2020v3n2p190

\title{
DEIXA EU TE CONTAR: existe alegria no meu "arraiá"
}

LET ME TELL YOU: there is joy in my "arraiá"

Déjame decirte: hay alegría en mi arraiá

\section{Débora Cristiana Alves Soares de Albuquerque ${ }^{1}$ Maria José de Pinho² Fabíola Andrade Pereira ${ }^{3}$ Wellington Mota de Sousa ${ }^{4}$ Marina Carla da Cruz da Cruz Queiroz ${ }^{5}$}

\section{RESUMO}

Este texto tem como objetivo relatar a vivência de uma senhora em tempos de pandemia. Essa experiência ocorreu em uma cidade do interior do Tocantins e é fruto de um Projeto de Extensão da Universidade Federal do Tocantins por meio do GATI- Grupo de Apoio a Terceira Idade. O intuito do Projeto é promover ações que elevem a autoestima e também a qualidade de vida dos idosos, demonstrando que mesmo em tempos difíceis a universidade tem conduzido ações de extensão dando visibilidade para o idoso.

\footnotetext{
${ }^{1}$ Discente do curso de Pedagogia Licenciatura Plena da Pontifícia Universidade Católica de Goiás, PUC GOIÁS, Brasil, deboracristiana1@gmail.com

2 Doutora do curso de Licenciatura de Pedagogia da Pontifícia Universidade Católica de São Paulo, PUC/SP, Brasil, mjpgon@mail.uft.edu.br.

${ }^{3}$ Doutora do curso de Licenciatura de PEDAGOGIA da Universidade Federal da Paraíba, UFPB, Brasil, fabagnes@mail.uft.edu.br.

${ }^{4}$ Discente do curso de Licenciatura de Educação Física do Instituto de Ensino Superior do Sul do Maranhão, IESMA, Brasil.wellington.mota@uft.edu.br.

${ }^{5}$ Discente do curso de Licenciatura de Pedagogia daUniversidade Estadual de Goiás, UEG, Brasil, marinacarlla@gmail.com.
} 


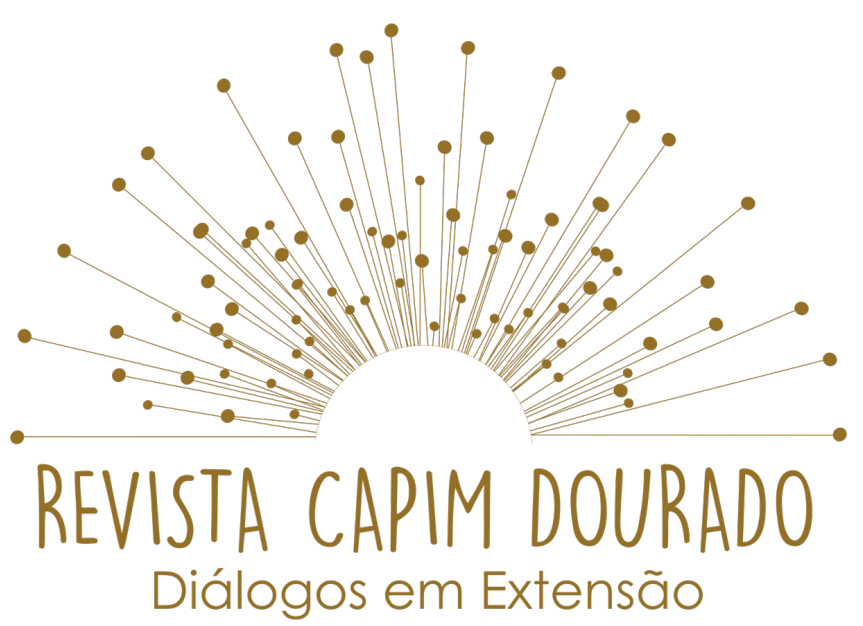

ISSN n² 2595-7341

Vol. 3, n. 2, Maio-Agosto, 2020

DOI: http://dx.doi.org/10.20873/uft.2595-7341.2020v3n2p190

PALAVRAS-CHAVE: Terceira Idade; Atividade Física; Complexidade.

\begin{abstract}
This text aims to report the experience of a lady in times of pandemic. This experience took place in a city in the interior of Tocantins and is the result of an Extension Project at the Federal University of Tocantins through the GATISupport Group for the Elderly. The aim of the Project is to promote actions that raise self-esteem and also the quality of life of the elderly, demonstrating that even in difficult times the university has conducted extension actions giving visibility to the elderly.
\end{abstract}

KEYWORDS: Third Age; Physical activity; Complexity.

\title{
RESUMEN
}

Este texto tiene como objetivo informar la experiencia de una dama en tiempos de pandemia. Esta experiencia tuvo lugar en una ciudad del interior de Tocantins y es el resultado de un Proyecto de Extensión en la Universidad Federal de Tocantins a través del Grupo de Apoyo GATI para Personas Mayores. El objetivo del proyecto es promover acciones que aumenten la autoestima y también la calidad de vida de las personas mayores, demostrando que incluso en tiempos difíciles, la universidad ha llevado a cabo acciones de extensión para dar visibilidad a las personas mayores.

PALABRAS CLAVE: Tercera edad; Actividad física; Complejidad.

Recebido em: 31.03.2020. Aceito em: 19.04.2020. Publicado em: 30.05.2020. 


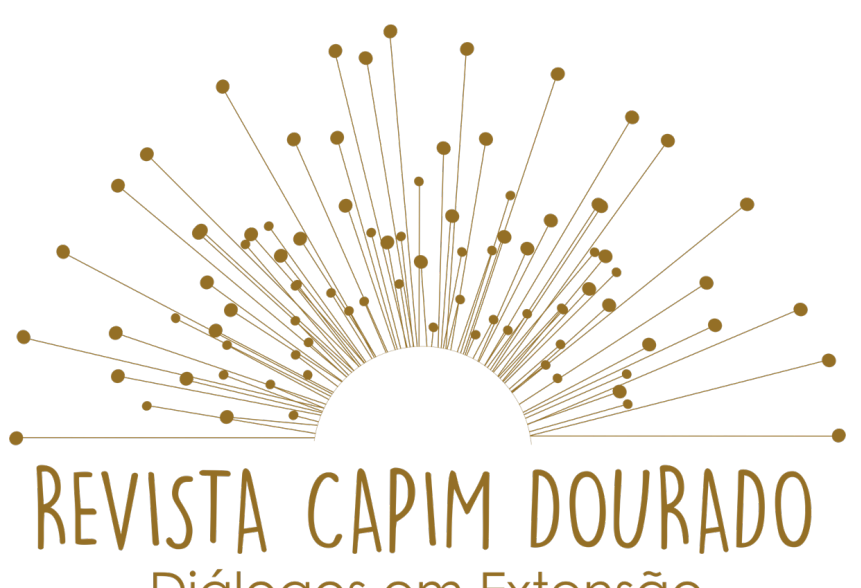

Diálogos em Extensão

ISSN n 2595-7341

Vol. 3, n. 2, Maio-Agosto, 2020

DOI: http://dx.doi.org/10.20873/uft.2595-7341.2020v3n2p190

\section{Essa vida, minha vida}

Dona A é uma senhora emblemática, tem 67 anos e veio do Maranhão, mas está no Tocantins há muitos anos e por isso se considera filha desta Terra. Ela é avó de 15 netos e 06 bisnetos, e reside no interior do Tocantins e tem vivido muitas experiências e lutas nessa vida e por isso dona A é de um carisma inigualável. Por onde anda, faz muitas amizades, conquistas pessoas e defende o ideal de valorizar a vida, de se ter a alegria estampada no rosto mesmo nos momentos difíceis.

Contar histórias, sorrir, dançar, costurar, são umas das muitas habilidades que essa senhora tem. Dona de uma vivacidade muito grande, demonstra emoção ao ser convidada para falar do GATI- Grupo de Apoio da Terceira Idade e que ela faz questão de participar com muita vitalidade. Dona A é aposentada, foi agente de saúde e isso a fez com que se tornasse muito conhecida e querida na comunidade e até já foi cotada para ser candidata a vereadora, fato que ela disse não concordar "porque eu não estou ficando doida".

Dona A diz que está em relacionamento sério há muitos anos, mas que já sofreu muito nessa vida porque passou por momentos difíceis: "uma mulher roubou meu marido, mas eu fui lá e roubei ele de volta"; esse é apenas um dos "causos" que ela conta sorrindo e dizendo que a vida é difícil, mas que devemos saber enfrentar as adversidades, porque "a vida é assim mesmo, cheia de surpresas boas e ruins". 


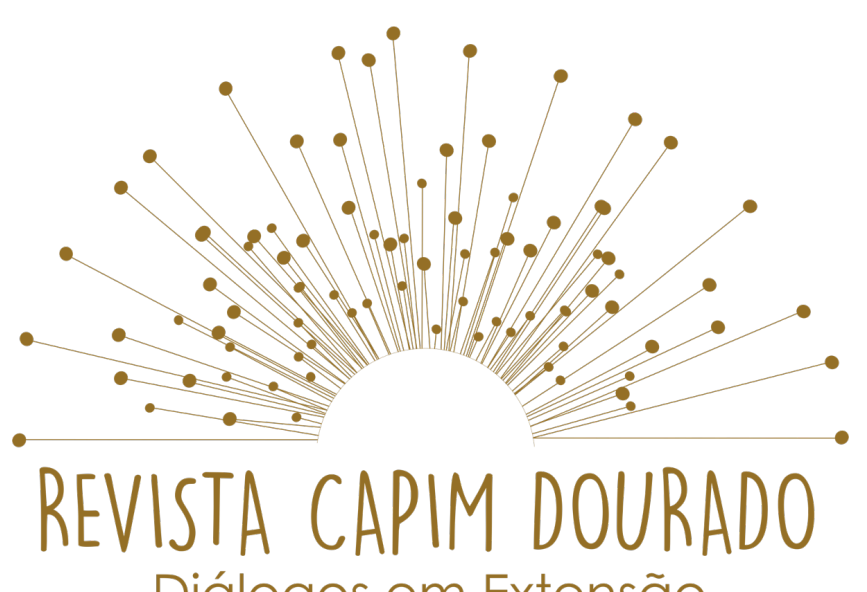

Diálogos em Extensão

ISSN n 2595-7341

Vol. 3, n. 2, Maio-Agosto, 2020

DOI: http://dx.doi.org/10.20873/uft.2595-7341.2020v3n2p190

Em isolamento domiciliar, há cerca de 104 dias, dona A afirma que essa pandemia tem trazido tristeza, medo e a perda de uma amiga. Para vencer a dor, ela passa o dia em sua casa fazendo serviços domésticos, trabalhos artesanais, "crochetando" tapetes e é claro, ensaiando para o "Arraiá da Alegria" que online e em que ela tem o papel da rainha do arraial.

Ela nos diz também, em uma conversa de vídeo chamada, que a coisa que mais gosta de fazer, é dançar forró, "daquele bem agarradinho", mas que agora devido a pandemia isso ficou impossível. Para ela, "isso é uma atividade física muito boa; dançar faz bem para a saúde". Dona A também está preparando uma live sobre a quadrilha online que ocorrerá em sua comunidade, que será a comemoração da festa de São João em casa. É com toda essa narrativa de vida que Dona A nos faz refletir sobre como a vida é entremeada de contratempos, de riso e choro, de alegria e tristeza, de vida e de morte, de emoção e razão.

\section{Eu e a universidade}

A vivência desse relato ocorreu na cidade de GG, no ano de 2020, no período da pandemia. O Projeto de Extensão GATI-Grupo de Apoio à Terceira Idade vinha exercendo suas atividades normalmente por meio de debates, roda de conversa, sorteios de rifas, atividades lúdicas, passeio turístico, corrida de rua e muitas outras ações. Isso era rotina na vida dos idosos antes da pandemia.

Porém, com advento do isolamento social, a universidade precisou se reinventar e encontrou outras formas de desenvolver as ações de extensão. Assim, a partir de março de 2020, o GATI- Grupo de Apoio à Terceira Idade, 


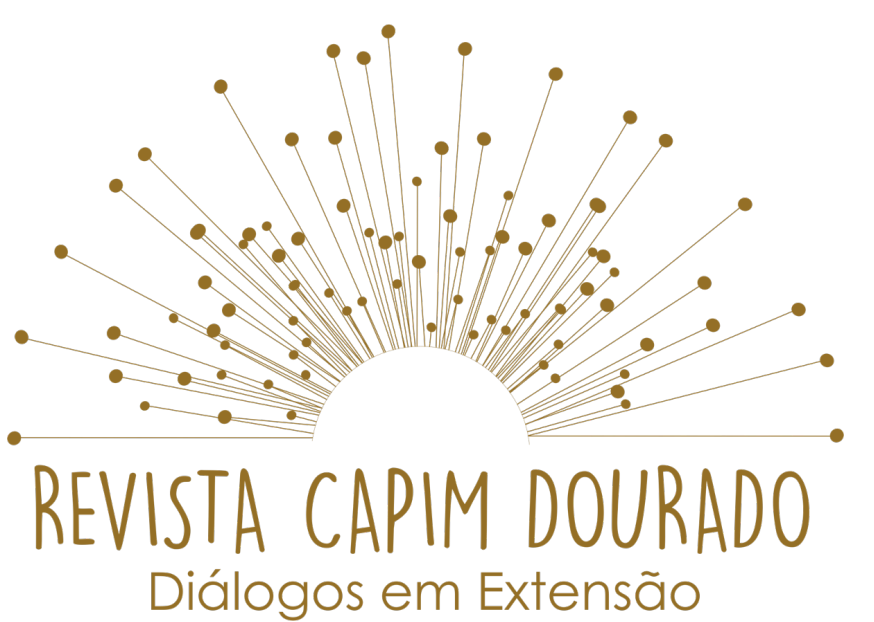

ISSN n² 2595-7341

Vol. 3, n. 2, Maio-Agosto, 2020

DOI: http://dx.doi.org/10.20873/uft.2595-7341.2020v3n2p190

doravante GATI, passa a repensar sua forma de atuar. Ao perceber que os idosos isolados em casa, longe dos netos, filhos e dos amigos estavam com problemas de saúde mental, propuseram algumas intervenções.

Nesse caso, esse relato de vivência está relacionado à linha de extensão "Esporte e Lazer", porque a forma de dar respostas a toda essa circunstância foi por meio de atividades físicas, pelo lazer e pelo esporte. Mas como fazer isso de forma distante, já que as pessoas precisam manter o isolamento social?

Dona A relata que esse momento de isolamento foi doloroso até que ela e os demais colegas começaram a compreender sobre a situação. Ela mesma ficou depressiva e precisou de atendimentos. Mesmo em adversidades piores que passou na vida e que não foram poucas, jamais tinha enfrentado tanta angústia, medo e tristeza. Foi nesse instante que o GATI age com muita sensatez e propõe atividades online sobre exercícios físicos como dança, atividades de alongamento e também propõe roda de conversa, escuta atenta e trabalhos manuais. Ao falar dessas ideias do GATI, dona A reviveu. Como ela mesma relata: "falar do GATI para mim é renascer, reviver e se reconhecer". Então, a primeira solução pensada para essa situação que se apresentava foi planejar reuniões online, via WhatsApp, google meet, ligações telefônicas, tudo com o objetivo de integrar o grupo utilizando meios tecnológicos. O propósito era não deixar o grupo se dispersar e se distanciar. Era a busca pela integração e pela interação, mesmo que a distância.

De acordo com a complexidade de Morin (2018), podemos refletir que o conhecimento científico nos trouxe algumas certezas, mas também outras 


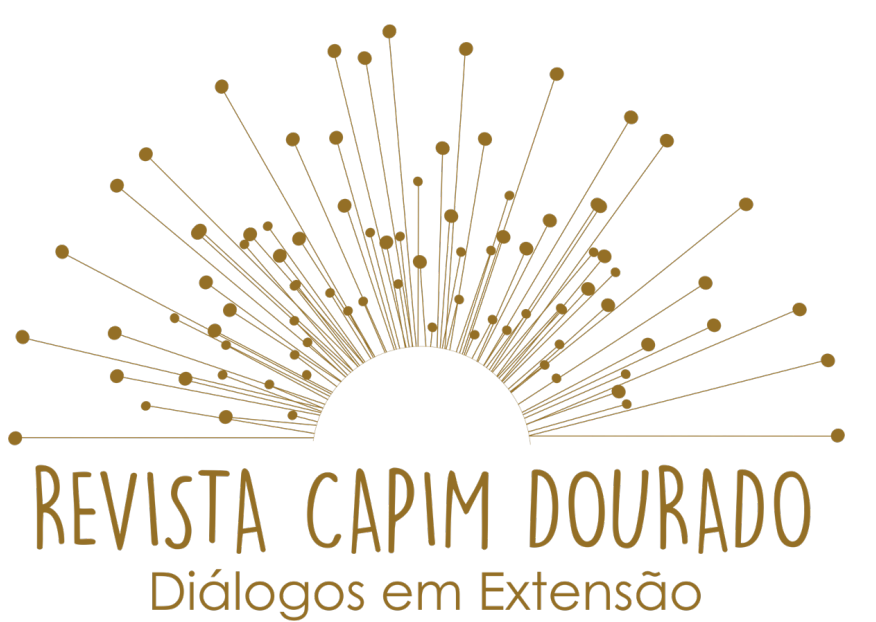

ISSN n² 2595-7341

Vol. 3, n. 2, Maio-Agosto, 2020

DOI: http://dx.doi.org/10.20873/uft.2595-7341.2020v3n2p190

incertezas. O homem precisa compreender que na vida tudo está agrupado e coeso e que a vida tem um sentido e um propósito. Então, de forma contextualizada a complexidade utiliza os problemas do cotidiano em uma situação que o saber se amplia e isso faz com que a fragmentação da ciência seja superada.

Essa situação ocorre dentro de um princípio de autorregeneração, que é a capacidade que nós temos de enfrentar a vida e responder aos desafios que nos sãos apresentados. Para Morin (2018), é o princípio recursivo e para dona A "é a energia que a pessoa tem de levantar, sacudir a poeira e seguir em frente com mais coragem e sabedoria". Assim, na aprendizagem da vida o pensamento complexo nos provoca a questionar sobre nossa capacidade de aprendizagem, de flexibilidade, numa situação de ajustes em um ciclo organizador.

Foi nesse contato entre comunidade acadêmica e comunidade partícipe que se promoveu essa troca de experiências diversas, de forma que houve ganhos para ambas as partes. Um movimento desse tipo favorece que a academia e a comunidade externa aprendam juntas, cada uma respeitando suas especificidades e princípios. A primeira dificuldade enfrentada tem sido reaprender a conviver em isolamento. É uma situação nova que o GATI em diálogo com seus pares a cada dia vem enfrentando. Para isso, foi necessário agendar horários, realizar reuniões online, distribuir funções e marcar datas para discutir sobre os resultados.

Claro que são múltiplos os desafios que o grupo tem encarado nesse cenário de Covid-19, porém, o vínculo tem sido mantido por meio das tecnologias e ações 


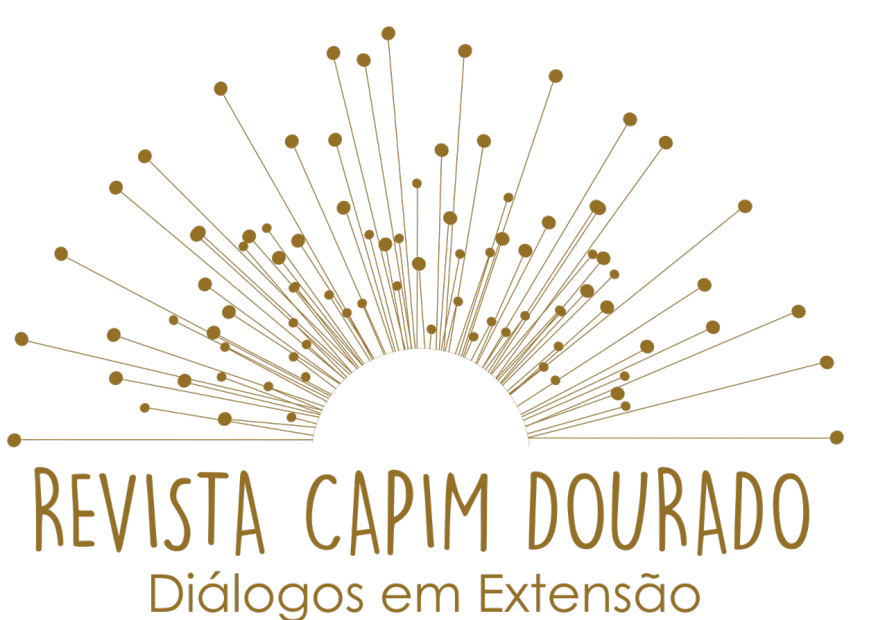

ISSN n² 2595-7341

Vol. 3, n. 2, Maio-Agosto, 2020

DOI: http://dx.doi.org/10.20873/uft.2595-7341.2020v3n2p190

de escuta sensível, diálogo constante, atendimento psicológico e as atividades físicas têm colaborado bastante. É interessante compreender que agora nossas relações com a vida e com as pessoas e também com o planeta precisam ser a preocupação central desse processo. No linguajar de dona A "não dá para inventar a roda. Agora é lutar para viver e um ajudar o outro no que for possível".

\section{Resultados positivos e reflexões finais}

Nesse diálogo bonito sobre o conhecimento da vida, dona A mostra que a universidade mesmo distante estimula iniciativas que integram ciência e comunidade. É a universidade dialogando com o saber popular, entrelaçando sabedoria popular e conhecimento científico. Para dona A o resultado dessas ações faz os integrantes do GATI pensar soluções e alternativas. A consequência dessas intervenções tem demonstrado a satisfação de trabalhos dos partícipes na produção de trabalhos artesanais, na participação de atividades físicas online, o que colabora para qualidade de vida dos idosos.

Dona A, a protagonista deste relato de vivência revela ainda que todo esse trabalho está mantendo sua vida ativa já que agora precisa pensar, planejar e organizar uma comemoração de São João em Casa (online). Isso mantém todo seu tempo preenchido e "aí não vejo a hora passar devido as muitas tarefas".

São ações simples, mas desafiadoras que colocam "a mente para pensar e o corpo para mexer", porém promovem uma educação significativa. Todo o envolvimento dos idosos e integrantes do grupo apontam para aprimoramento 


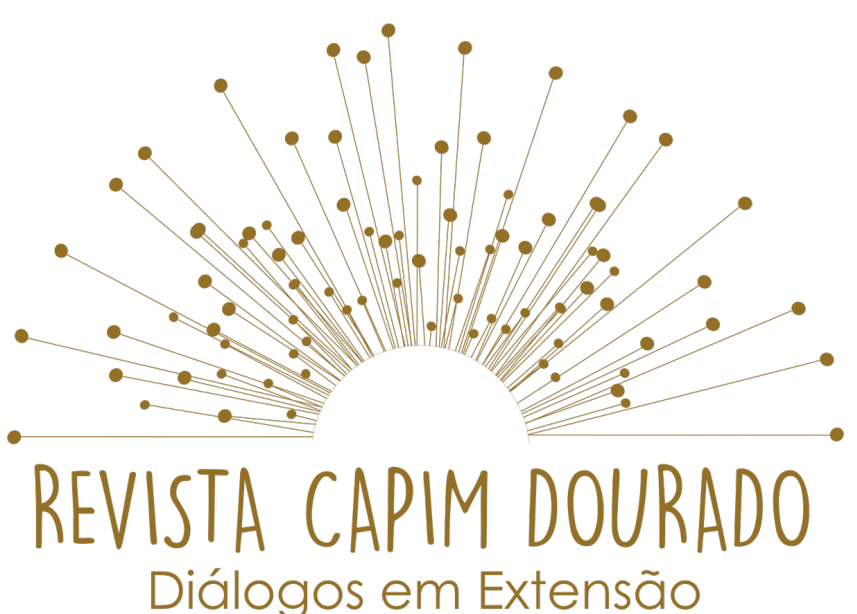

ISSN n² 2595-7341

Vol. 3, n. 2, Maio-Agosto, 2020

DOI: http://dx.doi.org/10.20873/uft.2595-7341.2020v3n2p190

do pensar sobre o conhecimento e sua relação com a vida, conhecimento compartilhado, troca de experiências, o caminhar na coletividade é que move a sociedade para pensar sobre os problemas que nos afligem.

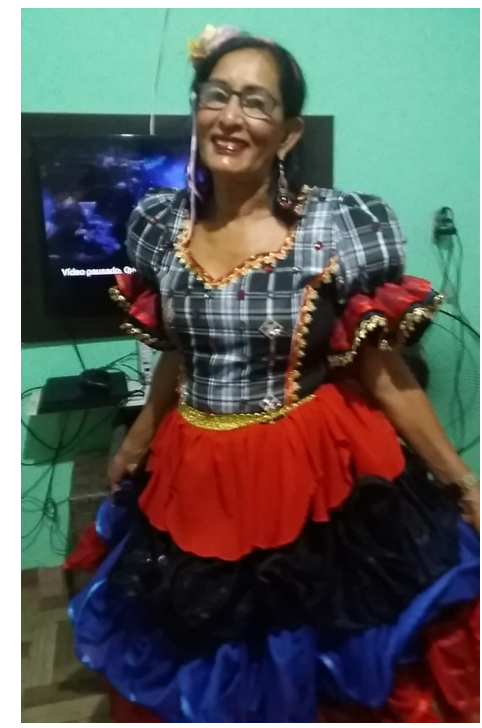

Figura 01: Dona A: São João em Casa. Créditos: arquivo pessoal da autora. Capturada em 29 de junho de 2020, em GG, Tocantins, Brasil.

Do ponto de vista da complexidade temos que lidar com situações de ordem e desordem, porque na vida a situação não é linear, mas imprevisível. É esperado que encontramos formas de sobreviver diante dessa pandemia e que possamos aprender algo de bom com essa situação. Aprender a ser mais humano, ter humildade, sensibilidade com a dor do outro, ter resiliência e compreensão do que é o verdadeiro amor. Somos seres incompletos, estamos 


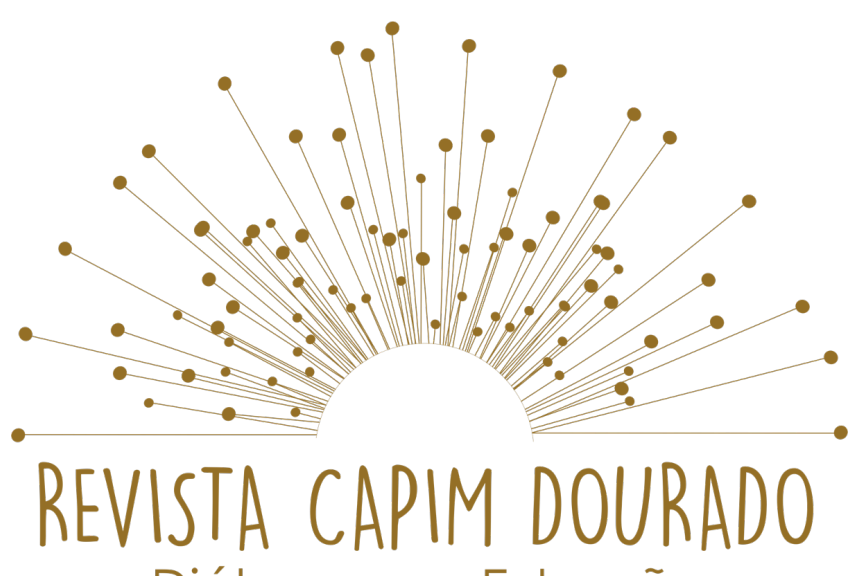

Diálogos em Extensão

ISSN n 2595-7341 Vol. 3, n. 2, Maio-Agosto, 2020

DOI: http://dx.doi.org/10.20873/uft.2595-7341.2020v3n2p190

em constante aperfeiçoamento e aprendizagem e precisamos cuidar uns do outro e também da nossa casa Terra.

\section{Referência}

MORIN, Edgar. Ciência com consciência. Rio de Janeiro: Bertrand Brasil, 2018. 